\title{
Urbanización neoliberal, tensiones y expectativas morales en la defensa del patrimonio: el caso del barrio Victoria, Santiago
}

\author{
Daniel Alfonso Valencia González \\ ORCID: https://orcid.org/0000-0001-8772-6653 \\ Comisión Económica para América Latina y el Caribe (CEPAL), Santiago, Chile.
}

\author{
Nicolás Salvador Angelcos Gutiérrez \\ ORCID: https://orcid.org/0000-0002-8044-0895 \\ Universidad Andrés Bello, Santiago, Chile. Correo electrónico: nicolas.angelcos@unab.cl
}

Esta investigación fue financiada por Fondecyt Postdoctorado 3160542 y Fondap Centro de Estudios de Conflicto y Cohesión Social 15130009.

\begin{abstract}
Resumen
En las últimas décadas, se ha destacado la emergencia de distintos conflictos contra los procesos de urbanización neoliberal, entre ellos, los conflictos asociados a la defensa del patrimonio. Dentro de esta literatura, se señala cómo, a partir de la defensa del barrio, las comunidades generan una forma de participación democrática que se opone a la lógica mercantil que orienta la evolución de nuestras ciudades. En este artículo, se tensionará este argumento a partir del análisis del proceso de patrimonialización del barrio Victoria en Santiago de Chile, barrio histórico que articula una identidad residencial con otra comercial, ligada al cuero y el calzado. A partir de relatos de vida, realizados a residentes antiguos y locatarios del barrio, se mostrará cómo detrás de la defensa de los barrios se articulan expectativas heterogéneas respecto a cómo debería ser la ciudad (quién y cómo habitarla), permitiendo, en algunos casos, excluir a algunos actores de la definición de comunidad y, en otros, ampliar la escala del conflicto. De este modo, se pretende contribuir a aquellos estudios que evalúan el potencial democrático de los conflictos ligados a la defensa del patrimonio.
\end{abstract}

\section{Palabras clave}

Barrio Victoria, expectativas morales, patrimonio cultural inmaterial, urbanización neoliberal

\section{Neoliberal urbanization, tensions and moral expectations about the defense of heritage:the case of Victoria neighborhood, Santiago of Chile}




\section{Introducción}

Tras la recuperación de la democracia en 1990, los estudios urbanos en Chile han dado cuenta de un cambio significativo en la cuestión urbana, tal como fue descrita a comienzos de los años setenta. Desde mediados de los años cuarenta hasta el golpe de Estado, la construcción de un hábitat residencial salvaje- campamentos ilegales-, impulsada por el movimiento de pobladores en alianza con los partidos políticos de centro e izquierda, constituía el epicentro de la conflictividad urbana y jugaba un rol decisivo dentro de las alternativas políticas que estaban en juego en esa época (Castells, 1973). Casi cincuenta años después, a través de distintas políticas habitacionales, el Estado ha logrado reducir de forma sustantiva el déficit de vivienda ${ }^{1}$, a tal punto que ya a mediados de los años 2000 se refería a la cuestión urbana como el problema de "los con techo", situando a la segregación residencial como el punto ciego de la nueva política de vivienda (Rodríguez y Sugranyes, 2004).

Esta relativa pacificación del conflicto por vivienda a comienzos del siglo $\mathrm{XXI}^{2}$ fue compensada por una ampliación de la conflictividad hacia otros fenómenos urbanos y nuevos actores sociales. Frente al "desierto de movilización popular" tras la "última toma" desarrollada en Peñalolén en 1999 (Salcedo, 2010), Sabatini y Wormald (2004) observaban el desarrollo de una acción colectiva innovadora respecto a los repertorios de movilización en décadas pasadas, que implicaba la conformación de un actor urbano interclasista, cuyo objetivo era detener los efectos negativos de la segregación residencial, en este caso, la instalación de un vertedero. En la misma línea, Ducci (2004), analizando las "batallas urbanas", destaca cómo la defensa de la calidad de vida contra un proyecto que es percibido como una amenaza (construcción de una carretera, nuevo desarrollo inmobiliario, instalación de antena de telefonía celular, construcción de una cárcel, etc.) se posiciona como el principal objetivo de la mayoría de las luchas observadas en Santiago desde la década de los noventa. Finalmente, analizando el mapa de conflictos urbanos desarrollados por la Corporación Sur, Renna (2010) muestra cómo, del total de 69 conflictos identificados en 30 comunas del Gran Santiago entre 2006 y 2009, un 48\% corresponde a conflictos por crecimiento urbano (expropiaciones, construcción en altura o el impacto provocado por la localización de proyectos viales o comerciales); un 23\% refiere a conflictos por vivienda (allegados, deudores, deterioro de la vivienda y tomas de terreno); un 19\% a impactos medioambientales; y un $10 \%$ corresponde a deterioro barrial (destrucción de patrimonio histórico o recuperación y ocupación de espacios públicos).

En este escenario, en los últimos años, ha comenzado a desarrollarse una incipiente agenda orientada a comprender el sentido de los conflictos por la defensa del patrimonio material e inmaterial de ciertos barrios. Al respecto, se ha destacado cómo distintas agrupaciones de vecinos, a través de una intensa participación, han logrado relevar el carácter patrimonial de ciertas zonas de Santiago, logrando detener el avance inmobiliario que amenaza el casco histórico de la ciudad (Canteros, 2011; Pineda, 2012; Uribe, 2014). Asimismo, se ha mostrado cómo distintos conflictos, a partir de movilizaciones específicas, han permitido la emergencia de una narrativa crítica hacia el modelo de urbanización neoliberal que se despliega desde fines de los setenta en la Región Metropolitana (Angelcos \& Méndez, 2017; Valencia, 2017). Finalmente, respecto a las motivaciones de quienes participan en estos conflictos, se ha destacado, por un lado, el sentimiento de nostalgia que orienta la disputa por la apropiación del espacio (Colin, 2017) y, por otro, la tensión entre el desarrollo de una crítica hacia la urbanización neoliberal y la defensa de una posición de clase heredada por medio del barrio (Méndez, 2018).

1 Según la última encuesta CASEN (2017), el déficit habitacional alcanza las 497.615 viviendas, más de 100.000 unidades respecto a la medición anterior. Esta situación representa un cambio importante respecto a la tendencia a la baja que se observaba en mediciones anteriores, sólo interrumpida por el terremoto del año 2010.

2 En los últimos años, distintos investigadores han observado la reemergencia del movimiento de pobladores en Chile (Angelcos y Pérez, 2017; Castillo, 2014; 2017; Romero, 2018), destacando la centralidad que tiene el marco del "derecho a la ciudad" en la definición de sus reivindicaciones. 
La mayoría de estas contribuciones se ha centrado en el estudio de movilizaciones exitosas, es decir, que han logrado el reconocimiento de ciertos barrios como "Zonas Típicas"3 por parte del Estado y que se han constituido en espacios de socialización política para la formación de un número significativo de activistas de izquierda, lo que explica, en parte, el desarrollo de un discurso relativamente homogéneo contra la urbanización neoliberal y el despliegue de formas contestatarias de participación ciudadana. En este artículo, por el contrario, se analiza el proceso de patrimonialización del barrio Victoria, el cual, pese a ser parte del casco histórico de Santiago -su origen se remonta a mediados del s. XIX - no ha sido reconocido como "Zona Típica" por el Estado chileno, aun cuando se registra una iniciativa por parte de los vecinos el año 2010. Asimismo, es un barrio que articula una identidad residencial con otra comercial, asociada al rubro del cuero y el calzado, el cual ha sido fuertemente afectado por la globalización de la economía y el consiguiente aumento de las importaciones, destacando la masificación del calzado de origen chino. En este sentido, la pregunta que orienta este artículo es: ¿cuáles son los argumentos que los antiguos residentes y trabajadores del barrio Victoria producen para justificar el valor patrimonial del barrio? Inspirados por la sociología pragmática de la crítica (Boltanski, 2009; Boltanski \& Thévenot, 1999), el análisis se centrará en las expectativas morales que tienen los individuos, es decir, sus nociones acerca de lo que el barrio debería ser, las cuales, de acuerdo con esta perspectiva, se activan en el curso de disputas públicas, en este caso, en torno a su patrimonialización. A este respecto, se demostrará la hipótesis según la cual, aun cuando es identificable una percepción común respecto al deterioro de la calidad de vida del barrio, se articulan expectativas morales heterogéneas que se apoyan en tres puntos de vista normativos: por una parte, los antiguos residentes definen su comunidad a partir de la cité doméstica; y, por otra, los locatarios, en su defensa del patrimonio, articulan expectativas relativas a la cité industrial y a la cité cívica. En este sentido, los resultados muestran cómo los procesos de patrimonialización pueden apoyarse en visiones de la ciudad heterogéneas, en algunos casos excluyentes, que tensionan las formas de participación democrática que promueven usualmente los activistas en este tipo de conflictos (Canteros, 2011).

Para demostrar esta hipótesis, el artículo se basa en una investigación realizada entre los años 2016 y 2017 en el barrio Victoria. La producción de información se llevó a cabo a través de observaciones etnográficas y la realización de 12 relatos de vida. La investigación contempló entrevistas a residentes antiguos del barrio, en especial, a personas pertenecientes a la junta de vecinos Gabriela Mistral II, y a locatarios ligados al rubro del cuero y el calzado. En primer lugar, desarrollaremos el marco teórico del artículo, mostrando, por un lado, la relación entre la urbanización neoliberal y defensa del patrimonio, y, por otro, el enfoque de la sociología pragmática. En segundo lugar, explicaremos la metodología del estudio, detallando las particularidades del barrio Victoria. En tercer lugar, analizaremos los argumentos que los antiguos residentes y locatarios del barrio dan para justificar el valor patrimonial del barrio. En este apartado, desarrollaremos la hipótesis que orienta el artículo. Finalmente, en las conclusiones, presentaremos una síntesis de los principales hallazgos de la investigación y su contribución a los estudios sobre patrimonialización y conflictos urbanos.

\section{Urbanización neoliberal: efectos y consecuencias sobre el espacio urbano}

A mediados de la década del setenta, en respuesta a la crisis de la sociedad industrial, tal como fue observada por Henri Lefebvre (1974), Manuel Castells (1974) y David Harvey (1977), comienza una reestructuración radical, tanto de la economía mundial como del núcleo institucional que, hasta ese entonces, la sostenía. Esta transformación- descrita como neoliberalismo-implicaba, entre otras cosas, la desindustrialización de las principales economías mundiales, en cuyo lugar se desarrolla el sector

3 Esta declaratoria busca proteger aquellos sectores urbanos o rurales que presentan una unidad estilística y que tienen un interés artístico, arquitectónico, urbanístico o social. 
financiero y terciario; la desregulación del mercado, así como la mercantilización de bienes públicos; y la globalización de la economía, que reduce de forma significativa la capacidad de control de los Estados nacionales sobre los flujos económicos.

En la implementación y desarrollo del proyecto neoliberal, las ciudades juegan un rol fundamental, puesto que éstas funcionan como un espacio de producción, reproducción y expansión de dicho modelo (Harvey, 2013). Los espacios urbanos, de esta forma, pasan a ser sectores estratégicos del despliegue de proyectos neoliberales y de apropiación y dominio capitalista (Theodore, Peck y Brenner, 2009). Bajo esta lógica, se desarrollan, en las principales metrópolis del mundo, proyectos de urbanización neoliberal, promovidos por actores estatales, en articulación con un intenso desarrollo del sector privado e inmobiliario (López-Morales, Gasic y Meza, 2012).

La urbanización neoliberal descansa en procesos de "destrucción creativa", donde se destruyen, parcialmente, disposiciones institucionales y acuerdos políticos por medio de reformas que buscan crear una nueva infraestructura económica y urbana orientada al mercado y a la mercantilización de diferentes bienes y servicios (Harvey, 2007). Así, diversas zonas urbanas funcionan como laboratorios para experimentos de políticas de desarrollo neoliberal, tales como la creación de zonas empresariales, la reducción de impuestos locales y la mercantilización del valor de uso del suelo.

De esta manera, se promueve un constante proceso de renovación urbana, destruyendo y reconstruyendo los diferentes espacios y lugares de la ciudad con el fin de favorecer los intereses del capital y otorgarle cada vez una mayor supremacía al mercado (Colin, 2017). Estos procesos de renovación urbana, asociados a la construcción de carreteras, megacentros de consumo urbano, edificios en altura, entre otros, tienen como principal foco los centros históricos de las ciudades, debido a las externalidades positivas que tienen dichos espacios y a la fácil recuperación de inversión de capital que traen consigo (Valencia, 2017). Asimismo, estos procesos conllevan una expansión de la ciudad, arrasando y absorbiendo con los barrios antiguos de las metrópolis, convirtiendo los diferentes elementos de la urbe en objetos de lucro (Navarro, Fini y Castro, 2017).

\section{Neoliberalismo y patrimonialización en Chile}

El fenómeno anteriormente descrito se presenta en la mayor parte del mundo y, de manera específica, en los diferentes espacios urbanos de América Latina. En la última década, las ciudades latinoamericanas se han mostrado como el epicentro de una serie de transformaciones territoriales ligadas al proceso de globalización del capitalismo y a la implementación de políticas de desarrollo neoliberal (Hidalgo, 2004). A este respecto, Santiago de Chile se muestra como un caso emblemático de la región y que ejemplifica de gran forma estos procesos de urbanización.

Las reformas neoliberales, impulsadas por la dictadura a fines de los años setenta, han tenido como consecuencia un aumento en la especulación sobre el suelo y una mayor intensificación, desde la década de 1990, del desarrollo de proyectos inmobiliarios en altura y densificación urbana en el centro de Santiago (Contreras, 2011). Así, ha existido un gran número de operaciones inmobiliarias en la ciudad, las cuales han destruido sectores completos, reemplazando construcciones antiguas con un valor histórico patrimonial por nuevos edificios y/o construcciones más modernas (Colin, 2017).

Estas transformaciones han generado nuevas resistencias por parte de distintos actores. Dentro de las estrategias desplegadas para contener la renovación urbana de tipo neoliberal, han destacado, en la última década, las iniciativas de patrimonialización, sobre todo desde la controversia asociada al uso residencial/comercial del barrio Bellavista a mediados de los años noventa y la declaración de "Zona Típica" del Barrio Yungay y el Barrio Matta-Viel (Rojas, 2014).

Dentro de estas luchas, la apelación por lo patrimonial ha transitado desde la defensa por lo "monumental y arquitectónico" a la reivindicación de las relaciones comunitarias que otorgan identidad al barrio (Uribe, 
Tabla 1

Lógicas de justificación

\begin{tabular}{|c|c|c|c|c|c|c|}
\hline & Inspirada & Doméstica & Cívica & Del renombre & Mercantil & Industrial \\
\hline $\begin{array}{l}\text { Forma de } \\
\text { evaluación }\end{array}$ & $\begin{array}{c}\text { Gracia, no } \\
\text { conformidad, } \\
\text { creatividad }\end{array}$ & Estima, reputación & Interés colectivo & Renombre & Precio & $\begin{array}{l}\text { Productividad, } \\
\text { eficiencia }\end{array}$ \\
\hline $\begin{array}{l}\text { Relación } \\
\text { elemental }\end{array}$ & Pasión & Confianza & Solidaridad & Reconocimiento & Intercambio & Vínculo funcional \\
\hline
\end{tabular}

Fuente: Elaboración propia a partir de Boltanski y Thévenot (1999).

2014). Así, la patrimonialización aparecería como una estrategia de resistencia frente a los intereses económicos que orientan la urbanización neoliberal, la cual es percibida como indiscriminada, sin criterio ni identidad. Los residentes asocian lo patrimonial a determinados valores, tales como la historia, la pertenencia y el afecto, los cuales serían incompatibles con la rentabilidad (Silva, 2015). Asimismo, la patrimonialización representaría una forma de generación de valor simbólico, económico e, incluso, turístico de los espacios que habitan las personas (Valencia, 2019).

Sin embargo, aun cuando la defensa de lo patrimonial pueda ser utilizada como una estrategia de resistencia por parte de algunas organizaciones de vecinos, generando espacios de participación ciudadana y de revaloración del espacio público, investigaciones recientes muestran cómo la patrimonialización también se vincula con distintas estrategias de reproducción de clase que, a través de dicho proceso, refuerzan fronteras con otros grupos sociales (Angelcos, 2021; Angelcos \& Méndez, 2017; Méndez, 2018). ).

\section{Sociología pragmática, expectativas morales y conflictos urbanos}

La sociología pragmática de la crítica es un programa de investigación desarrollado en Francia, durante los años ochenta, cuyo principal autor es Luc Boltanski. Este programa proviene de la sociología crítica impulsada por Pierre Bourdieu, la cual, a juicio de Boltanski, subestima o ignora las capacidades críticas de los individuos. Para abordar estas capacidades, la sociología pragmática de la crítica se da por tarea "observar, describir e interpretar las situaciones en las cuales las personas realizan críticas, es decir, disputas" (Boltanski, 2009, p. 47).
En un libro escrito junto a Laurent Thévenot (1991), Boltanski buscó modelizar la actividad de los actores y las competencias que despliegan en el curso de disputas públicas, identificando, para ello, el sentido de justicia que movilizan tanto para justificar como para criticar el orden social. A partir de esto, lograron mostrar cómo los actores, en el curso de diferentes disputas, movilizan distintas expectativas morales, es decir, nociones ordinarias acerca de lo que el mundo debería ser, que se apoyan en puntos de vista normativos que aspiran a ser universales. Dicho en otras palabras, cuando los individuos evalúan una situación, por ejemplo, la construcción de un edificio o un centro comercial, movilizan expectativas morales acerca de lo que la ciudad debiera ser. Para unos, podría ser un avance para modernizar la ciudad, desde el punto de vista de la eficiencia, para otros, sin embargo, podría ser un atentado contra el interés colectivo. En ambos casos, lo que se valora (eficiencia, interés colectivo) aspira a tener una validez para el conjunto de la población. Siguiendo esta lógica, Boltanski y Thévenot identificaron seis lógicas de justificación o cités ${ }^{4}$ que definen tanto las formas de evaluación de los individuos, como el tipo de relaciones que se privilegian en el curso de la disputa. En la tabla 1, se destacan sus principales conceptos.

Siguiendo este enfoque, se entenderá el proceso de patrimonialización del barrio Victoria como una disputa en torno a la cual los individuos movilizan expectativas morales heterogéneas respecto a lo que el barrio debiera ser. En este caso, se ponen en tensión tres puntos de vista normativos distintos: por una parte, los antiguos residentes definen su comunidad a partir de la cité doméstica, en la cual se valoran los lazos de confianza que se han establecido a lo largo de los años, frente a los cuales los nuevos residentes, los locatarios, la población flotante del barrio y los inmigrantes latinoamericanos

4 En el Nuevo espíritu del capitalismo (2002), Boltanski y Chiapello identificaron una séptima cité que bautizaron "por proyectos". 
aparecen como una amenaza; por otra parte, los locatarios apoyan sus expectativas morales tanto en la cité industrial, desde la cual se valoran los vínculos funcionales con los inmigrantes latinoamericanos, como en la cité cívica, desde la cual se construye un interés colectivo basado en la pertenencia nacional.

\section{Metodología}

El presente artículo se basa en un estudio de caso realizado sobre el proceso de patrimonialización del barrio Victoria con un enfoque metodológico de tipo cualitativo, inductivo y exploratorio. El método de estudio de caso, como señala Martínez Carazo (2006), se presenta como una herramienta valiosa de investigación, ya que permite registrar representaciones, subjetividades y conductas de las personas, como también hacer un aporte en la construcción de una perspectiva teórica más robusta por medio de una situación social específica. Así, debido a la profundidad del conocimiento obtenido, es que se pueden llevar a cabo generalizaciones de un carácter analítico a otras investigaciones de perspectivas y condiciones teóricas similares.

La muestra de la investigación se compuso por residentes y locatarios del lugar, con un rango de edad de 50 a 76 años. El motivo por el cual se seleccionaron estas personas, y no otras con un conocimiento técnico sobre los procesos de patrimonialización, es que se buscaba conocer la historia del lugar, sus tradiciones, lugares valorados y significados desde el relato de aquellos sujetos que han desarrollado gran parte de su vida en el barrio y participado de manera activa en la formación y producción del espacio. A su vez, cabe señalar que, dentro de los entrevistados, se encuentra una persona que participó de manera activa de los movimientos emergidos desde el barrio para la defensa del oficio del cuero y el calzado.

Por otra parte, las técnicas de recolección de información correspondieron a relatos de vida y observaciones etnográficas. Sobre la primera, ésta se llevó a cabo con el fin de reconstruir la historia del barrio e identificar la experiencia social e individual de los sujetos en el lugar. A las personas se les planteaba una pregunta inicial donde se les invitaba a contar su historia en el sector $\mathrm{y}$, a medida que se avanzaba en la entrevista, se iban realizando nuevas preguntas según los temas de interés que surgían. Se realizaron 12 entrevistas: 6 a residentes pertenecientes a la junta de vecinos Gabriela Mistral II y 6 a locatarios del barrio. Los relatos obtenidos fueron transcritos y analizados utilizando un enfoque de teoría fundamentada (Charmaz, 2006).

En lo que respecta a las observaciones etnográficas, éstas se llevaron a cabo en cada visita que se realizó al barrio. Se utilizó esta técnica para poder contextualizar los procesos de vida de las personas en el barrio y, además, comprender los vínculos de ellas con el espacio y su desarrollo histórico-estructural (Achilli, 2005). En estos acercamientos se tomaron notas de campo que posteriormente fueron analizadas. En ellas, se logró dar cuenta del día a día en el lugar, su ambiente y las interacciones sociales que se daban entre los diferentes actores que habitan el sector.

Finalmente, como una fuente de información complementaria, se revisaron y analizaron documentos facilitados por personas asociadas a la directiva de los locatarios del barrio y afiches encontrados en los diferentes espacios del sector.

\section{El caso del barrio Victoria}

El barrio Victoria tiene sus orígenes a mediados del s. XIX y se encuentra ubicado en el sector sur de la comuna de Santiago (Figura 1). Su historia ligada al cuero y el calzado se remonta al año 1902, fecha en la que comenzaron a aparecer las primeras suelerías en el lugar. El barrio, desde sus inicios, ha presentado la coexistencia de dos ejes que lo caracterizan: uno residencial y otro comercial.

En sus comienzos, además de contar con talleres en los cuales se trabajaba el cuero y el calzado, el lugar se caracterizaba por la existencia de diferentes locales ligados a una vida bohemia, con una alta presencia de restaurantes y bares por el sector. Sin embargo, con el paso del tiempo, dichos locales fueron desapareciendo y perdiendo presencia en el territorio. 
Figura 1

Ubicación del barrio Victoria

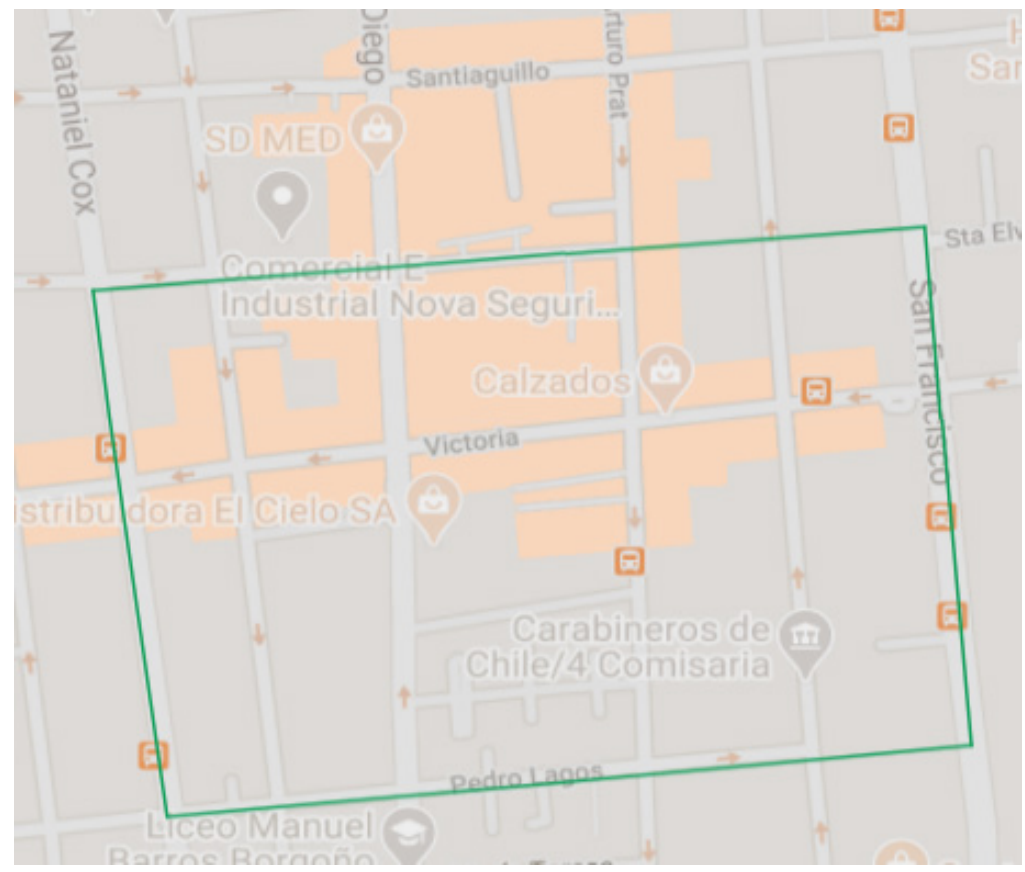

Fuente: Elaboración propia a partir de Google Maps.

Con la desaparición de estos locales, y con el auge que comenzaba a tener la industria del calzado en el país en la década de 1970, empezó un crecimiento y apogeo de la industria del cuero y el calzado en el barrio. En esa época, el lugar se posicionaba como uno de los más relevantes para el rubro en el país, ya que, más que encontrarse talleres que se dedicaran a la venta de zapatos en sí, lo que existía era una gran cantidad de locales y talleres que se dedicaban a la producción y venta de materia prima para la elaboración del calzado nacional.

A principios de la década de 1980, con los cambios que generó la adopción de políticas neoliberales en el país, y la modernización a nivel mundial de los procesos productivos en la industria del cuero y el calzado, el sector comenzó a vivir una crisis y una merma en sus ventas y producción. La disminución de la industria nacional del cuero y el calzado afectó directamente al barrio, trayendo consigo diversos problemas económicos a los locatarios y el mismo cierre de una gran cantidad de talleres. Para sobrevivir a dichas crisis, algunos productores comenzaron a establecer locales de venta de calzado, lo que le da la fisonomía actual al lugar.

Pese al carácter tradicional del barrio, en los últimos años, se han desarrollado importantes proyectos inmobiliarios que han cambiado de forma significativa el sector. Al respecto, se pueden observar grandes torres de departamentos que interrumpen el paisaje de construcciones antiguas (Figura 2), arrasando con espacios y edificaciones que, desde la perspectiva de los residentes, representaban la historia del barrio y de sus vidas. Este proceso no ha sido experimentado sin resistencias por parte de la comunidad de vecinos, los cuales presentaron una solicitud al Consejo de Monumentos Nacionales para que el barrio fuera reconocido como Zona Típica ${ }^{5}$.

Finalmente, la densificación del centro de Santiago asociada a la llegada de migrantes de origen latinoamericano ha tensionado la identidad de los vecinos del lugar, donde, como veremos, se identifican

5 Desde el centro cultural Matta-Sur, se declara la disposición inicial para incorporar el barrio Victoria, sin embargo, se desecha por no tener "valor arquitectónico" (Álvarez, 2011). 
Figura 2

Nuevas edificaciones en pleno barrio Victoria, perspectiva desde calle San Diego

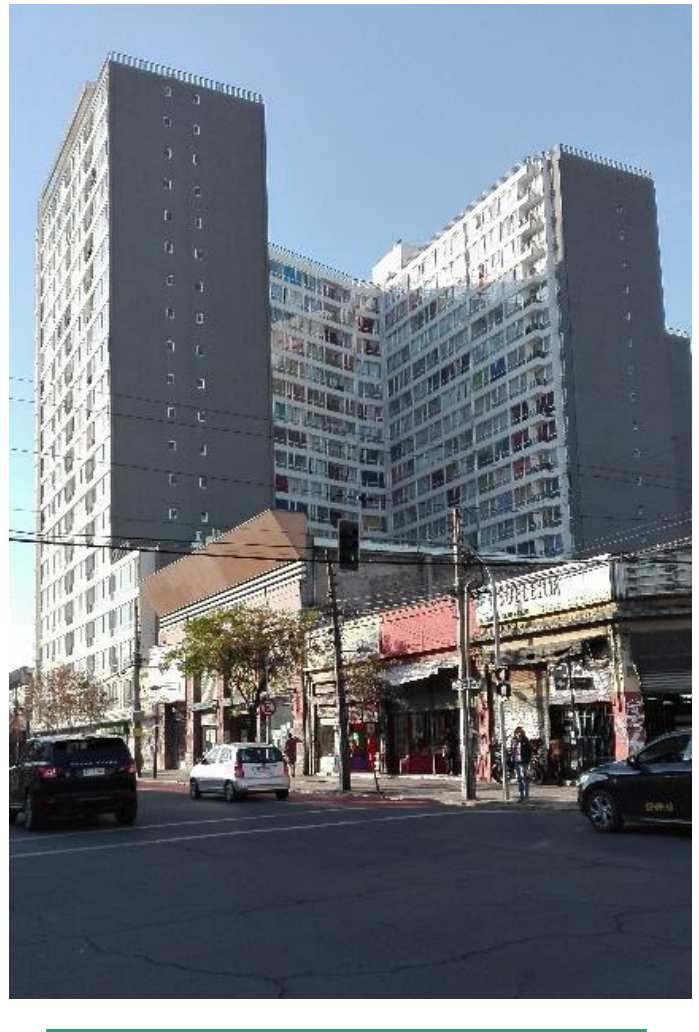

Fuente: Elaboración propia.

discursos contradictorios respecto a la posición que ocupan dentro del imaginario del sector.

\section{Motivaciones y estrategias para la defensa del barrio: el rescate de la vida de barrio y del oficio del cuero y el calzado}

Los procesos de urbanización y las políticas económicas neoliberales implementadas en el país desde fines de los años setenta han tenido impactos significativos tanto en los residentes como en los locatarios asociados a la industria del cuero y el calzado: por un lado, para los antiguos residentes, la vida cotidiana se ha deteriorado por la densificación en altura, la construcción de ciclovías y la llegada de nuevos habitantes al sector; por otra parte, para los locatarios, el desarrollo de una economía globalizada representa una fuerte amenaza para la existencia de su actividad, marcada por un fuerte sello artesanal. Ahora bien, pese a que las experiencias de pérdida y amenaza son heterogéneas, ambos actores buscan, a través de diferentes estrategias y acciones, rescatar el barrio, ya que éste opera como un soporte para la construcción de sus identidades.
Al rescate de la vida de barrio: la definición de la comunidad de vecinos. Entre los residentes del barrio Victoria circula una percepción generalizada respecto al deterioro que ha tenido la vida de barrio respecto a épocas pasadas. Para criticar las nuevas relaciones que se dan en el sector, se apoyan en un punto de vista normativo que, para Boltanski y Thévenot, correspondería a la cité doméstica. Tal como propone Colin (2017) para el caso de Matta-Viel, entre los vecinos predomina un sentimiento de nostalgia asociado a la vida comunitaria que, desde su perspectiva, caracterizaba su vida cuando niños y les permitía reconocerse como parte de un mismo grupo. Para ellos, se trataba de una vida auténtica, basada en lazos de confianza y tranquila, es decir, libre de delincuencia. En esta forma de vida, destacan las relaciones afectivas entre vecinos, la apropiación simbólica del espacio y las fiestas realizadas en comunidad.

Entre los vecinos era una vida como muy comunitaria, de saludos, de preguntar cómo está. Usted salía y era otra cosa, nosotros le hacíamos navidad a los niños, el viejito pascuero venía, todos andaban hasta las dos de la mañana en sus bicicletas, jugando con sus muñecas y ahora no pueden. Usted sale a esa hora y le roban la bicicleta. (Florencia, 60 años, Residente)

Estas expectativas morales basadas en relaciones de confianza motivan el despliegue de acciones y estrategias que buscan rescatar aquello que se siente perdido y que representa una concepción de vida de barrio que se valora. De esta forma, se llevan a cabo acciones que tienen como objetivo reconstruir los lazos afectivos al interior de la comunidad.

La misma junta de vecinos nos estamos encargando de celebrar el día de la madre como se hacía años atrás ¿ya?, en hacer las fiestas populares del día del niño, el dieciocho de septiembre, nos juntamos una o dos juntas de vecinos, cerramos la calle y le pedimos al municipio que nos ayude con ciertas cosas, para integrar a los vecinos, porque estos barrios se han convertido en barrios más individualistas. (Sandra, 55 años, Residente) 
Como se puede observar, dentro de estas acciones, destacan distintas formas de apropiación simbólica del espacio, entre ellas, el rescate de tradiciones propias del mundo popular, las cuales, desde la perspectiva de los vecinos organizados, permiten combatir los valores individualistas que promueve la modernización neoliberal. Esto implica la revalorización de determinadas formas de vida consideradas como superiores por parte de los vecinos, los cuales, motivados por los recuerdos, emociones y memorias, sacralizan discursos patrimoniales en base a una revitalización de actividades del pasado en el presente (Figura 3).

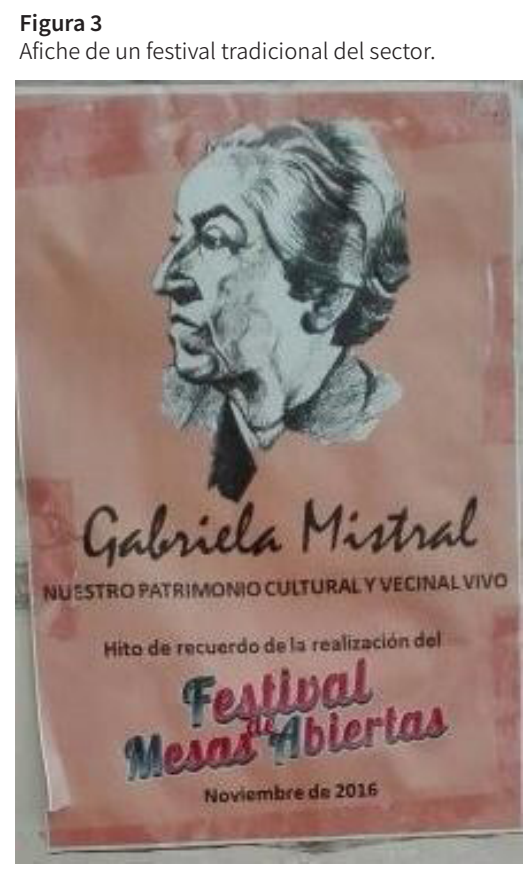

Fuente: Elaboración propia.

Esta forma de reapropiación del barrio ha sido asociada, en otros contextos, al desarrollo de una forma de participación democrática que tiene como objetivo la producción una ciudad más integrada y cohesionada, una cité cívica, desde la perspectiva de Boltanski y Thévenot. Así, se asocia la recuperación del patrimonio barrial a la construcción de una comunidad de vecinos cuya convivencia, tradiciones y valores se oponen a la fragmentación de la ciudad, expresada en el deterioro del espacio público y la prevalencia de valores individualistas. Sin embargo, en la definición de los límites simbólicos de esta comunidad, se excluye, al menos discursivamente, a distintos actores que actualmente son parte de la vida cotidiana del barrio.

Un primer actor excluido de la definición de comunidad refiere a los nuevos vecinos que han llegado al lugar gracias a los diferentes proyectos inmobiliarios que ocupan actualmente el territorio. Al igual que en el caso analizado por uno de los autores en otro artículo (Angelcos \& Méndez, 2017), los vecinos del barrio Victoria asocian el recambio generacional del sector con la promoción de valores individualistas y un sentimiento de desapego con el territorio, lo cual contrasta con su expectativa respecto a lo que la vida del barrio debería ser.

Como es toda gente nueva, cada una se encierra en sus casas, parece como los departamentos, nadie se mete con nadie ahora. Y antes aquí eran lindos, porque para las pascuas, los años nuevos, los dieciochos adornaban [...] El pasaje de nosotros está muerto ahora. Hay pura gente... uno como antigua, no se mete con esa gente joven. (Rosa, 76 años, Residente)

Un segundo actor excluido de la definición de comunidad que otorgan los vecinos refiere justamente a los locatarios del sector, cuya gran mayoría no reside en el barrio. Para los habitantes históricos, los locatarios, al no establecer una relación de propiedad sobre sus inmuebles, se mostrarían como personas despreocupadas e indiferentes respecto a la conservación del lugar. En este sentido, critican el vínculo funcional que establecen los locatarios con el barrio, a diferencia de las relaciones de confianza que, desde su perspectiva, deberían prevalecer al interior de la comunidad.

Hay un problema derivado con el trato, con el cuidado... con el modo de cooperar... y todo eso hace que sea diferente el trato de aquí con el de allá. A mí me interesa que esté limpio, que avance, que sea vea bien... porque somos dueños, es distinto [...] Lo que 
Figura 4

Ciclovías construidas en el barrio, calle Arturo Prat.

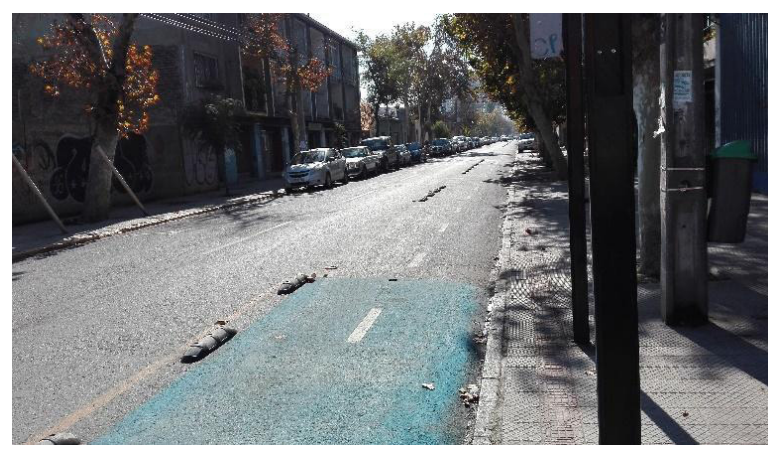

Fuente: Elaboración propia.

ha afectado ha sido el cuidado que hay que tener con las cosas. Nosotros las cuidamos y ellos no, porque no viven acá. (Antonio, 68 años, Residente)

Un tercer actor excluido por los vecinos de su definición de comunidad es la población que se moviliza por el sector, por ejemplo, los ciclistas y automovilistas que transcurren diariamente por las calles del barrio, dada su ubicación céntrica. Los procesos de renovación urbana, ligados, en este caso, a la construcción de una ciclovía en el barrio (Figura 4), han generado pérdidas de espacios y lugares a través de los cuales los vecinos desempeñaban prácticas y actividades asociadas al modo de vida que ellos buscan rescatar. De esta manera, aquellos sujetos que transcurren por el lugar, y que ocupan el espacio de manera temporal, encarnan y cristalizan las amenazas que traen los procesos de modernización y renovación urbana, siendo excluidos por parte los vecinos al momento de otorgarle un valor patrimonial al lugar.

Cuando no estaban esas pilas de cosas que nos pusieron para las ciclovías, cerrábamos la calle de Victoria a Pedro Lagos, y como venía música, venían títeres, venían juegos inflables, pero este año no sé qué vamos a hacer, no lo podemos hacer en otro lado porque tenemos que acarrear todo para allá. (Florencia, 60 años, Residente)

Finalmente, un último actor excluido de la definición de comunidad, que sustenta el imaginario patrimonial de los vecinos, está representado por los inmigrantes sudamericanos que se han instalado en las últimas décadas en el centro de Santiago. Para los residentes, los inmigrantes representan y materializan las amenazas propias de la globalización.
Lo otro que ha cambiado también, es que la gente extranjera hace mucha fiesta, en los departamentos la música zumba pa' todos lados. A veces disparan, disparan cuando llega la droga, disparan igual que en las poblaciones. (Marcela, 67 años, Residente).

Como se señaló al comienzo del análisis, uno de los elementos que los residentes valoraban del barrio era la tranquilidad. Al contrario, como se observa en las citas, los inmigrantes son representados como "ruidosos", "narcotraficantes" y "delincuentes", construyendo una otredad que materializa y contiene las fuerzas que amenazan y contaminan el ambiente del lugar (Tijoux, 2014). De esta manera, las formas de vida de los inmigrantes, desde la perspectiva de los antiguos residentes, no contribuirían a la revitalización del sector, sino, al contrario, se constituirían como uno de los tantos factores que amenazan la vida del barrio y su valor patrimonial.

De esta forma, en oposición a la construcción de una imagen de barrio inclusiva, los antiguos residentes, a través de la promoción de un punto de vista normativo que valora la confianza como relación elemental, construyen una definición de comunidad que excluye otros modos de vida y usos del territorio que no se corresponden con la visión nostálgica que elaboran para rescatar el valor patrimonial del lugar.

El oficio del cuero y el calzado: el rescate de lo nacional y perspectivas de integración en pos de la conservación del barrio y del saber-hacer tradicional. En la sección anterior, el rescate patrimonial del barrio es asociado por los residentes antiguos a un rescate de las relaciones de confianza que, desde su perspectiva, caracterizaban al barrio en épocas pasadas. En el caso de los locatarios, la globalización también representa una amenaza, pero referida al saber-hacer tradicional que identifica a la industria del calzado en ese sector. En este sentido, el rescate patrimonial del barrio articula dos puntos de vista normativos distintos: por una parte, anclado en la cité cívica, se identifica el interés colectivo con la defensa de lo nacional, a partir de lo cual se critica la "invasión" de productos extranjeros; y, por otra parte, 
se valora la llegada de inmigrantes sudamericanos a partir del vínculo funcional que se establece con ellos, lo que, desde el enfoque pragmatista, correspondería a la cité industrial.

Desde principios de los años ochenta, el barrio Victoria se enfrentó a la importación de productos chinos, lo que provocó crisis en la industria de calzado nacional, obligando al cierre de muchos talleres (Sepúlveda, Portales y Maturana, 2020). Las consecuencias de este proceso todavía son muy visibles en los testimonios de nuestros entrevistados:

Fue una cosa que fue de mercado, y esto se nos cerró a todos. Porque aquí quebraron fábricas grandes, chicas, medianas, talleres. Desapareció casi el noventa por ciento de las fábricas. Mingo cerró, los Collao en Viña, Concepción desapareció, Casen cerró, porque no había venta. Todo llegaba de afuera. (Pedro, 60 años, Locatario)

Esta crisis de la industria nacional del calzado no sólo implicó un problema económico para el sector, sino también la desvaloración de un saber-hacer tradicional que formaba parte de la identidad de los trabajadores. En este sentido, la modernización neoliberal ha significado una amenaza para el estatus de los locatarios, produciéndose un fenómeno de descalificación social (Paugam, 1991). Así nos lo relata una entrevistada:

Han tenido muchos que cambiar de trabajo, por ejemplo, a ser conserje, como no tienen muchos estudios, no pueden trabajar en otras cosas [...] Y ya los jóvenes no quieren aprender tampoco po', no les interesa. (Elizabeth, 50 años, Locataria)

Como se puede observar en la cita, las calificaciones que tenían los trabajadores del sector pierden valor en este nuevo escenario globalizado, expulsándolos hacia trabajos de menor estatus. Esto genera una ruptura en la trasmisión del oficio, ya que la adquisición de conocimiento tomaba la forma de un aprendizaje intergeneracional, el cual ya no genera interés en los más jóvenes.
Esta descalificación social impulsa la emergencia de un sentimiento nacionalista que los locatarios sitúan espacialmente en el barrio. Es desde esta perspectiva que surge, dentro de este actor, una reivindicación de lo patrimonial.

Pero algo que sea netamente nacional, de producción nacional, que sea elaborado por obreros chilenos, no lo vas a encontrar en otro lado. Entonces no tiene una doble estructura, es una sola y eso es un valor propio de este barrio. Y se puede cambiar a otro barrio, por ejemplo, si todos los locales se cambiaran a la calle Biobío, se demoraría su par de años en volver a tomar el espíritu que se tiene acá. Porque acá hay un espíritu que se ha estado estableciendo durante mucho tiempo. (Víctor, 63 años, Locatario)

Como se puede apreciar en los relatos, lo que más se destaca del producto que se encuentra en el barrio es que es un "calzado nacional" y "hecho por obreros chilenos". En este sentido, frente a las amenazas que representan la modernización neoliberal y el proceso de globalización para la construcción de su identidad como comunidad, los locatarios oponen un punto de vista normativo que asocia el interés colectivo- la defensa del patrimonio- al rescate de lo nacional.

Ahora bien, este rescate de lo nacional no se realiza de forma abstracta, sino que, como señalamos previamente, se inscribe espacialmente en el territorio. El barrio Victoria no representa solamente el lugar donde se ejerce este oficio, el cual podría ser trasladado eventualmente; representa también un espacio en que los locatarios han construido su identidad históricamente, marcado por los procesos de cambio, sufrimientos y luchas que conforman su experiencia social.

Esta asociación entre lo nacional, el oficio del calzado y la pertenencia al barrio ha motivado a los locatarios a realizar distintas acciones en defensa de lo patrimonial. Algunas de éstas han tenido un sentido más comercial, intentando revitalizar la venta del calzado en el barrio, $y$ otras un sentido directamente político, cuyo objetivo es 
el reconocimiento y protección del oficio por parte del Estado. Respecto al primer sentido, un locatario relata:

Nosotros trabajábamos de lunes a viernes y formábamos las ferias del calzado. Que fue... nos salvó harto. Porque las primeras ferias que hicimos aquí, en Victoria, las hicimos con una asociación que se llama APICCAL, que es una asociación del cuero y calzado. Esa asociación no existía, estaba muerta, y entre algunos sueleros formamos y sacamos adelante de nuevo, para pelear. (Pedro, 60 años, Locatario)

Como se puede apreciar, estas acciones implican una forma de apropiación del espacio que, a juzgar por lo analizado en la sección anterior, no es bien valorada por los antiguos residentes. Sin embargo, para los locatarios, representa una forma de revitalizar una actividad constitutiva del patrimonio nacional que, como se expuso, está fuertemente amenazada por los procesos de globalización. Lo anterior, se puede observar cuando, en el relato, se señala que dichas acciones fueron las que lograron "salvar" su oficio y les dieron las herramientas para poder "pelear" y mantenerse en el barrio.

Respecto al sentido político de las acciones realizadas por los locatarios, tiene una especificidad distinta a la reivindicación patrimonial impulsada por los antiguos residentes. A diferencia de la inscripción local que supone la defensa de relaciones de confianza al interior del barrio, la reivindicación de lo nacional asociada a la defensa del oficio del cuero y el calzado permite amplificar la escala del conflicto, integrando a otros rubros en la movilización. A continuación, un locatario describe un evento de protesta (asimismo, ver Figura 5):

Salimos de aquí, partimos acá y llegamos al centro. Fueron como cinco mil personas. Se llevaron detenido al Jorge, al hermano... al papá, se llevaron detenidos a otros. (Pedro, 60 años, Locatario)

La movilización que describe el locatario del sector se constituyó como un movimiento colectivo que buscaba la reivindicación de un oficio y un producto de carácter nacional. Ahora bien, a través de la revisión de documentos
Figura 5

Protesta realizada contra el ingreso del calzado chino

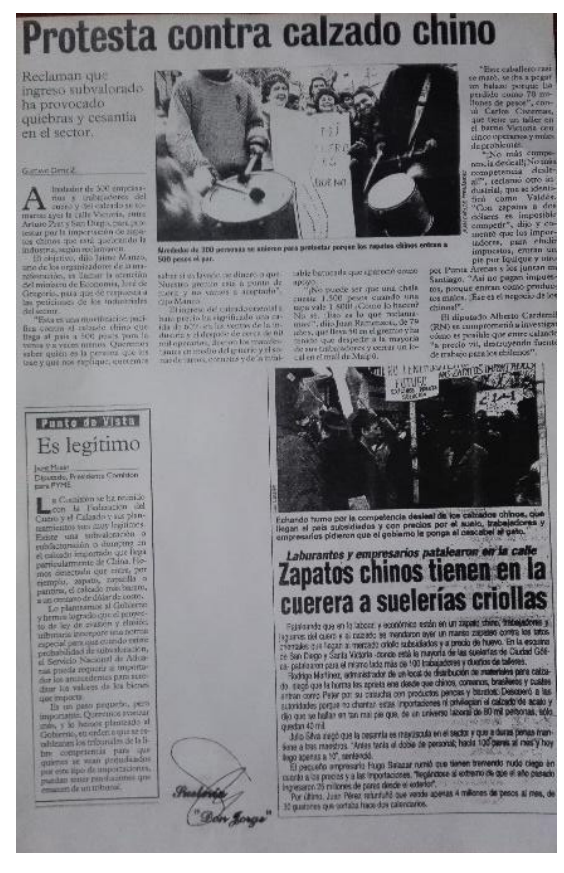

Fuente: Archivo facilitado por la directiva de la junta de locatarios del barrio Victoria.

facilitados por la directiva de los locatarios del barrio, se pudo apreciar que el movimiento, a pesar de que no logró mantenerse por un largo periodo de tiempo, generó, por un lado, la emergencia de un interés colectivo más amplio, integrando gente a nivel nacional del gremio del cuero y el calzado y grupos de otros oficios del país; y, por otro, una postura crítica y mayores grados de concientización frente a los factores estructurales que representaban una amenaza para ellos. En este sentido, identifican, tras la "invasión" de productos extranjeros, una desvalorización de los oficios artesanales nacionales, una desprotección frente a la implementación de políticas neoliberales y el desplazamiento de los saberes tradicionales por los procesos de modernización en curso.

En este sentido, a diferencia de la definición limitada de comunidad que moviliza a los antiguos residentes del lugar, emerge un discurso patrimonial que integra a 
otros actores dentro de la movilización. Esto se expresa claramente cuando, en una carta dirigida al expresidente Ricardo Lagos (Figura 6), el colectivo reivindicaba la figura del "patrimonio artesanal nacional", haciendo referencia al valor histórico y tradicional que se encuentra depositado en los diferentes oficios del país.

En esta misma dirección, a diferencia del discurso excluyente de los antiguos residentes respecto a los inmigrantes, para los locatarios, la inmigración peruana y colombiana representa una oportunidad para la revitalización del oficio, en este sentido, contribuye a la defensa de lo patrimonial y no representa una amenaza como en el discurso que vimos en la sección anterior.

El peruano es bueno, es gente honrada, es gente que es responsable. Tú le dices a las ocho y a las ocho está el maestro ahí. [...] Y después comenzaron a llegar los inmigrantes peruanos y colombianos, que son buenos aparadores... Yo creo que esto se ha sostenido gracias a la inmigración. (Pedro, 60 años, Locatario)

Como se observa, la llegada de inmigrantes se presenta como una solución y un mecanismo de mantención tanto de la actividad económica que caracteriza al barrio como también de un saber-hacer que se estaba perdiendo en el país. A los inmigrantes, entonces, se les representa como personas "buenas" y "honradas", en oposición a las representaciones negativas que construían los antiguos residentes. Esta diferencia se explica por el tipo de integración que están evaluando ambos actores: en los términos propuestos por Sabatini y Salcedo (2007), para los vecinos del sector, se evalúa la integración comunitaria de los inmigrantes, la cual es criticada por no subordinarse a las formas hegemónicas de convivencia en el barrio; mientras que, para los locatarios, se evalúa su integración funcional al rubro del calzado, coherente con la cité industrial que promueven, la cual es percibida como una oportunidad más que como una amenaza.

Finalmente, una última diferencia entre el discurso movilizado por los antiguos residentes y los locatarios es la evaluación que se realiza respecto a la modificación del paisaje del barrio y, con ello, la llegada de nuevos residentes.
Figura 6

Carta dirigida al expresidente Ricardo Lagos

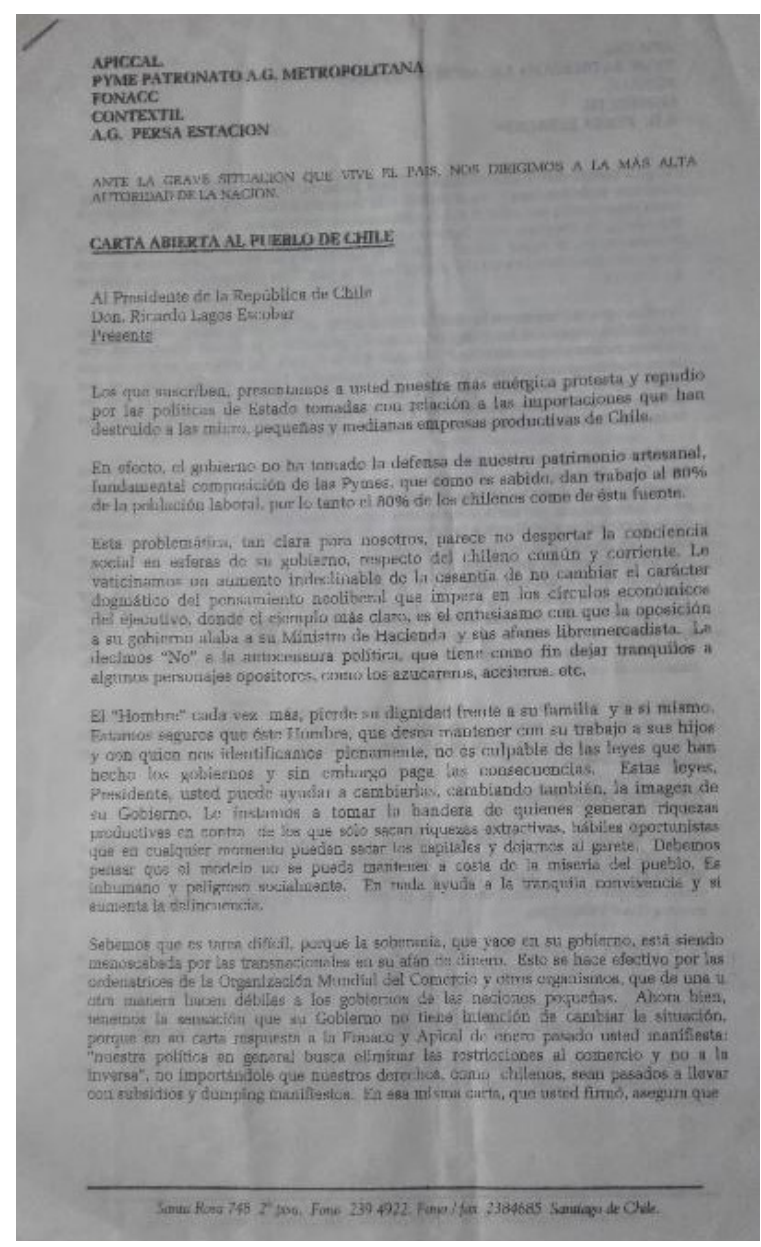

Fuente: Archivo facilitado por la directiva de la junta de locatarios del barrio Victoria.

Como se señaló previamente, para los antiguos residentes, la construcción de grandes edificios, además de dañar el patrimonio material del barrio, abre la puerta para que lleguen nuevos vecinos, cuyas formas de vida, desde su perspectiva, amenazan las relaciones de confianza que ellos defienden. Para los locatarios, sin embargo, mientras no se destruyan y desplacen talleres y/o construcciones históricas del rubro, los proyectos inmobiliarios y el aumento en la población del barrio se evalúa positivamente, ya que 
contribuye a una revitalización del sector, al implicar un mayor flujo de gente y, en consecuencia, una mayor presencia de consumidores.

En síntesis, desde la perspectiva de los locatarios el valor patrimonial del barrio no refiere a la vida comunitaria que destacan los antiguos residentes, sino al oficio del cuero y el calzado que históricamente le ha dado identidad a este lugar dentro del imaginario santiaguino. Esto les ha permitido asociar la defensa del patrimonio barrial a conflictos que operan, a lo menos, a nivel metropolitano, superando, en parte, el carácter excluyente de la definición de comunidad que movilizan los antiguos residentes.

\section{Conclusión}

La literatura contemporánea en estudios urbanos ha destacado la emergencia de distintos conflictos que se han desplegado contra los efectos negativos de la globalización y los procesos de urbanización neoliberal asociados (Harvey, 2013; Soja, 2014). Entre estos, en los últimos años, destaca una incipiente agenda de investigación orientada a comprender el sentido de los conflictos asociados a la defensa del patrimonio, subrayando la emergencia de una forma de participación democrática que se opone a la lógica mercantil que orienta el crecimiento de nuestras ciudades (Canteros, 2011).

A partir del análisis de las justificaciones que antiguos residentes y locatarios del barrio Victoria asocian al proceso de patrimonialización, se identificaron distintas expectativas morales que tensionan, por un lado, la emergencia de un discurso común respecto al valor patrimonial del barrio y, por otro, el lenguaje democrático que pareciera orientar este proceso. Como se pudo observar, en el caso de los antiguos residentes, sus distintas acciones están motivadas por un sentimiento de nostalgia respecto a las relaciones de confianza que estructuraban la vida del barrio en décadas pasadas, las cuales se verían amenazadas por la modernización neoliberal. Desde esta perspectiva, la llegada de nuevos habitantes al barrio sería rechazada por los antiguos residentes, en la medida que sus actitudes- despreocupadas, violentas, indiferentes- no calzarían con la definición de comunidad que ellos se esfuerzan por reconstruir. De esta forma, limitan su visión respecto a quiénes y cómo deberían habitar el barrio, excluyendo a distintos actores, tales como los jóvenes que llegan a vivir en los nuevos departamentos, la población flotante que circula por el sector y los inmigrantes latinoamericanos que se han instalado en el centro de Santiago durante las últimas décadas. Llama la atención que incluso los locatarios, asociados al rubro del cuero y el calzado, son excluidos de la comunidad por los antiguos residentes debido al vínculo funcional que defienden. En este sentido, la definición de comunidad que movilizan en el proceso de patrimonialización limita el alcance democrático de su reivindicación.

En el caso de los locatarios, su defensa del patrimonio barrial se asocia a la identificación entre el interés común y el rescate del oficio del cuero y el calzado que ha marcado históricamente la identidad de este sector dentro del imaginario santiaguino. En este caso, sus expectativas morales se asocian directamente con lo nacional, generando un discurso de oposición respecto a las consecuencias que ha tenido la globalización sobre la industria nacional. Este discurso les ha permitido escalar el conflicto, superando el nivel local e incorporando a otros actores dentro de sus estrategias de reconocimiento y protección dirigidas hacia el Estado. Aun cuando el uso que los locatarios hacen del barrio no se pueda restringir exclusivamente a lo comercial, en el sentido que también han desarrollo una fuerte identidad asociada a este sector, su posición dentro del lugar les ha permitido construir un discurso más inclusivo respecto a otras formas de habitar, integrando, dentro de su defensa del patrimonio, a inmigrantes peruanos y colombianos, los cuales son integrados funcionalmente en la reactivación del rubro. Asimismo, las transformaciones del paisaje urbano y la llegada de nuevos vecinos no son percibidas como una amenaza, sino como una oportunidad de renovación del sector, en la medida que no destruyan el comercio tradicional del barrio.

De esta forma, en continuidad con los estudios desarrollados por Angelcos y Méndez (2017), Méndez (2018) y Angelcos (2021), se puede observar cómo los 
procesos de patrimonialización suponen tensiones y expectativas morales heterogéneas respecto a quiénes son parte del barrio, cuál es su identidad y cuáles son los usos que se pueden movilizar en el territorio. Estas tensiones muchas veces son oscurecidas por el discurso de los activistas, quienes buscan enmarcar el conflicto en un discurso homogéneo contra la modernización neoliberal y sus consecuencias negativas respecto al cambio en el paisaje urbano y las formas de sociabilidad impersonal que se instalan.

\section{Referencias bibliográficas}

Achilli, E. (2005). Investigar en antropología social. Los desafíos de transmitir un oficio. Rosario: Laborde.

Álvarez, B. (25 deabril de 2011).Lamodernidad llegóa loszapateros de calle Victoria. La Tercera. https://www.pressreader. com/chile/la-tercera/20110425/282003258983127

Angelcos, N., \& Méndez, M. L. (2017). Struggles against territorial disqualification: mobilization for dignified housing and defense of heritage in Santiago. Latin American Perspectives, 44(3), 100-112. https://doi. org/10.1177/0094582X16682757

Angelcos, N. y Pérez, M. (2017). De la "desaparición” a la reemergencia: Continuidades y rupturas del movimiento de pobladores en Chile. Latin American Research Review, 52(1), 94-109. http://doi.org/10.25222/larr.39

Angelcos, N. (2021). Luchas por el significado del derecho a la ciudad: el caso de la coordinadora Plebiscito por La Reina, Santiago de Chile. Revista EURE, 47(140), 179-197.

Boltanski, L. (2009). De la critique. Précis de sociologie de l'émancipation. París: Gallimard.

Boltanski, L. y Chiapello, E. (2002). El nuevo espíritu del capitalismo. Madrid: Akal.

Boltanski, L. \& Thévenot, L. (1999). The sociology of critical capacity. European Journal of Social Theory, 2(3), 359377. https://doi.org/10.1177/136843199002003010
Boltanski, L. \& Thévenot. (1991). De la justification. Les économies de la grandeur. París: Gallimard.

Canteros, E. (2011). Las agrupaciones vecinales en defensa de los barrios. La construcción política desde lo local. Polis, 10(28), 85-99. http://dx.doi.org/10.4067/S0718$\underline{65682011000100006}$

Castells, M. (1973). Movimientos de pobladores y lucha de clases en Chile. Revista EURE, 3(7), 10-35.

Castells, M. (1974). La cuestión urbana. México: Siglo XXI.

Castillo, M. (2014). Competencias de los pobladores: potencial de innovación para la política habitacional chilena. Revista INVI, 29(81), 79- 112. http://dx.doi.org/10.4067/ S0718-83582014000200003

Charmaz, K. (2006). Constructing Grounded Theory: A practical guide through qualitative analysis. London: SAGE publications.

Colin, C. (2017). La nostalgia en la producción urbana: la defensa de barrios en Santiago de Chile. Revista INVI, 32(91), 91-111. http://dx.doi.org/10.4067/S071883582017000300091

Contreras, Y. (2011). La recuperación urbana y residencial del centro de Santiago: Nuevos habitantes, cambios socioespaciales significativos. EURE (Santiago), 37(112), 89-113. http://dx.doi.org/10.4067/S025071612011000300005

Romero, L. Del. (2018). Cartografías de la desigualdad: una década de conflictos de vivienda y nuevas resistencias en Santiago de Chile. Análisis del conflicto de la Maestranza de San Eugenio. EURE (Santiago), 44(132), 47-66. http:// dx.doi.org/10.4067/s0250-71612018000200047

Ducci, M. E. (2004). Las batallas urbanas de principios del tercer milenio. En De Mattos, Ducci, Rodríguez y Yañez (eds.), Santiago en la Globalización: ¿una nueva ciudad?, pp. 137-166. Santiago de Chile: Ediciones Sur, Libros Eure. 
Harvey, D. (1977). Urbanismo y desigualdad social. Madrid: Siglo XXI editores.

Harvey, D. (2007). Breve historia del neoliberalismo. Madrid: Akal.

Harvey, D. (2013). Ciudades Rebeldes. Del derecho de la ciudad a la revolución urbana. Madrid: Akal.

Hidalgo, R. (2004). De los pequeños condominios a la ciudad vallada: las urbanizaciones cerradas y la nueva geografía social en Santiago de Chile. EURE (Santiago), 30(91), 29-52. http://dx.doi.org/10.4067/S0250-71612004009100003

Lefebvre, H. (1974). La production de l'espace. Paris: Anthropos.

López-Morales, E., Gasic, I. R. y Meza, D. (2012). Urbanismo pro-empresarial en Chile: Políticas y planificación de la producción residencial en altura en el pericentro del gran Santiago. Revista INVI, 27(76), 75-114. http:// revistainvi.uchile.cl/index.php/INVI/article/view/732

Martínez Carazo, P. (2006). El método de estudio de caso: estrategia metodológica de la investigación científica. Pensamiento \& Gestión, (20), 165-193. https://www. redalyc.org/articulo.oa?id=64602005

Méndez, M. L. (2018). Neighborhoods as arenas of conflict in the neoliberal city: practices of boundary making between "us" and "them". City \& Community, 17(3), 737-753. https://doi.org/10.1111/cico.12326

Navarro, M., Fini, D. y Castro, D. (2017). Urbanización neoliberal y resistencias sociales en la ciudad de Puebla. Geograficando, 13(1), e019. https://doi. org/10.24215/2346898Xe019

Paugam, S. (1991). La disqualification sociale : essai sur la nouvelle pauvreté. Paris : PUF.

Pineda, J. (2012). Produciendo un barrio de zona típica. Ensamblando actores híbridos para pensar un barrio patrimonial. Contenido, Arte, Cultura y Ciencias Sociales, 2(1), 41-65.
Renna, H. (2010). La situación actual de los movimientos sociales urbanos. Autonomía, pluralidad y territorialización múltiple. Revista Electrónica DU\&P. Diseño Urbano y Paisaje, 7(20). http://dup.ucentral.cl/pdf/20_ movimientos_sociales_urbanos.pdf

Rodríguez, A. y Sugranyes, A. (2004). El problema de vivienda de los "con techo". EURE (Santiago), 30(91), 53-65. http:// dx.doi.org/10.4067/S0250-71612004009100004

Rojas, L. (2014). Hacia el desarrollo sostenible de los barrios patrimoniales de Santiago: la comunidad como generadora de desarrollo en base al patrimonio cultural. Planeo, (15). http://revistaplaneo.cl/2014/04/15/haciael-desarrollo-sostenible-de-los-barrios-patrimonialesde-santiago-la-comunidad-como-generadora-dedesarrollo-en-base-al-patrimonio-cultural/

Sabatini, F. y Wormald, G. (2004). La guerra de la basura de Santiago: desde el derecho a la vivienda al derecho a la ciudad. EURE (Santiago), 30(91), 67-86. http://dx.doi. org/10.4067/S0250-71612004009100005

Sabatini, F., \& Salcedo, R. (2007). Gated communities and the poor in Santiago, Chile: functional and symbolic integration in a context of aggressive capitalist colonization of lower class areas. Housing Policy Debate, 18(3), 577 606. https://doi.org/10.1080/10511482.2007.9521612

Salcedo, R. (2010). The Last Slum: Moving from Illegal Settlements to Subsidized Home Ownership in Chile. Urban Affairs Review, 46(1), 90-118. https://doi. org/10.1177/1078087410368487

Sepúlveda, U., Portales, F. y Maturana, F. (2020). Experiencias de resistencia y agencia espacio-laboral de trabajadores de un barrio tradicional frente a cambios globalizadores: el Barrio Victoria, Santiago de Chile. Izquierdas, (49), 11771197. Disponible en http://izquierdas.cl/ediciones/2020/ numero-49\#

Soja, E. (2014). En busca de la justicia espacial. Valencia: Tirant Humanidades. 
Silva, A. C. (2015). El barrio patrimonial: imaginarios identitarios urbanos y producción de lo público en una ciudad intermedia de la provincia de Buenos Aires. Revista Colombiana de Antropología, 51(1), 53-78. http://hdl. handle.net/11336/8616

Theodore, N., Peck, J. y Brenner, N. (2009). Urbanismo neoliberal: la ciudad y el imperio de los mercados. Temas sociales, (66), 1-12. http://www.sitiosur.cl/r.php?id=898

Tijoux, M. E. (2014). El otro inmigrante "negro" y el nosotros chileno. Un lazo cotidiano pleno de significaciones. Onteakin, (17), 1-15. http://onteaiken.com.ar/ver/ boletin17/art-tijoux.pdf
Uribe, N. (2014). Patrimonialización comunitaria en barrios de Santiago: los casos de las zonas típicas de Viel y Yungay. Apuntes, 27(1), 80-93. http://dx.doi.org/10.11144/ Javeriana.APC27-1.pcbs

Valencia, M. (2017). Tensiones entre procesos de patrimonialización y modernización neoliberal. El caso de los paisajes culturales modernos: conjuntos habitacionales y barrios obreros en América Latina en el siglo XX. Revista de Urbanismo, (36), 3-16. http:// dx.doi.org/10.5354/0717-5051.2017.45198

Valencia, M. (2019). ¿Gentrificación en zonas patrimoniales? Estudio de cinco casos en Santiago de Chile. Revista INVI, 34 (95), 71-99. http://dx.doi.org/10.4067/S071883582019000100071 